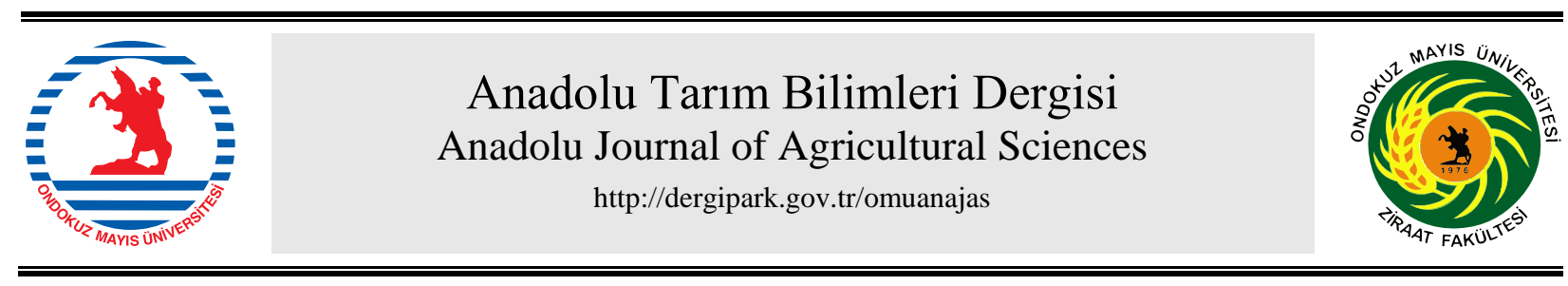

\title{
Araştırma/Research
}

Anadolu Tarım Bilim. Derg./Anadolu J Agr Sci, 33 (2018) ISSN: $1308-8750$ (Print) 1308-8769 (Online) doi: 10.7161/omuanajas. 450842

\section{Oryantal tütünde el gruplarına göre verim ve randıman özellikleri}

\author{
Dursun Kurt ${ }^{\mathrm{a} *}$, Güngör Y1lmaz \\ ${ }^{a}$ Ondokuz Mayls Üniversitesi,vBafra Meslek Yüksekokulu, Bitkisel ve Hayvansal Üretim Bölümü, Samsun \\ ${ }^{b}$ Gaziosmanpașa Üniversitesi, Ziraat Fakültesi, Tarla Bitkileri Bölümü, Tokat \\ *Sorumlu yazar/corresponding author: dursun.kurt@omu.edu.tr
}

Geliş/Received 04.08.2018

Kabul/Accepted 17.09.2018

\begin{abstract}
ÖZET
Oryantal tütünlerde hasat, el gruplarının olgunlaşmasıyla aşağıdan yukarıya doğru yapılmaktadır. Bu çalışmada, farklı lokasyonlarda yetiştirilen bazı oryantal tip tütün genotiplerinin el grupları, verim ve randıman değerleri bakımından incelenmiștir. Tesadüf blokları deneme desenine göre 3 tekrarlı kurulan denemeler Orta Karadeniz Bölgesi tütün üretim alanlarında yer alan 4 lokasyonda (Erbaa-Evciler, Erbaa-Karayaka, Gümüşhacıköy, Bafra), 2017 yılında yapılmıştır. Materyal olarak bölgeden toplanan 21 hat ile 4 standart genotip kullanılmıştır. Kırım işlemi üç elde tamamlanmış, el grupları ayrı ayrı değerlendirilmiştir. Hatlar arasında Gümüşhacıköy’de birinci ve ikinci kırım ile Bafra'da birinci kırım dışında kalan verim değerleri istatistiki olarak önemli bulunmuştur. Randıman bakımından ise Evciler ve Bafra'nın birinci kırımları dışında kalan kırımlarda, hatlar arasında önemli fark tespit edilmiştir. Mahsul veriminin oluşmasında ilk kırımların \% 28.0, ikinci kırımların \% 42.4 ve üçüncü kırımların \% 29.6 oranlarında etkisi olmuştur. Mahsul randımanı en yüksek Evciler'de (\% 90), en düşük Bafra' da (\% 52) tespit edilirken, kırımların randımana katkısı sırasıyla \% 25.8, \% 39.4 ve \% 34.8 olarak tespit edilmiştir.
\end{abstract}

\section{Hand groups oriented yield and grade index characters of oriental tobaccos}

\section{ABSTRACT}

Harvest was performed from lower part to upper part in oriental tobaccos with advancing of hand group's maturity. In this study, hand groups of some oriental tobacco genotypes grown in different locations were evaluated in terms of yield and grade index values. Experiment was planned in randomized blocks design with three replications and conducted four locations from tobacco production areas of Middle Black Sea Region (Erbaa-Evciler, Erbaa-Karayaka, Gümüşhacıköy, Bafra) in 2017. 21 lines and four standard genotypes obtained from this region were used as material. Harvest was completed by three hands and each hand group was evaluated separately. Among the lines, yield means were found to be significant except for those of first and second harvests in Gümüşhaciköy and second harvest in Bafra. As for grade index, a significant difference was detected among lines except for first harvest in Evciler and Bafra locations. Crop yield consisted of the first, second and third harvests at the rate of \% 28, \% 42.2 and \% 29.6, respectively. Grade index was the highest in Evciler (\% 90) and the lowest in Bafra locations. The contribute of harvests to grade index was found to be $25.8 \%, 39.4 \%$, $34.8 \%$ respectively.

\section{Giriş}

Dünyada 128 ülkede, 4.3 milyon ha alanda yaklaşık 7.5 milyon ton tütün üretimi yapılmaktadır. 74 bin ton üretim ile 10. sırada yer alan Türkiye, dünya oryantal tütün üretiminde ilk sıradadır (Anonim, 2018a). Türkiye bu üretiminin \%17'sini Karadeniz Bölgesinde yapmaktadır. Karadeniz Bölgesinin \% 40’1 Basma tütün tipi olup, harmanlarda yaklaşık \% $4-12$ oranında kullanılmaktadır (Anonim, 2018b).
Anahtar Sözcükler:

Basma

Hasat

Nicotiana tabacum L.
Keywords:

Basma

Harvest

Nicotiana tabacum L.

254 Bu makale Dursun Kurt' un doktora teziyle ilişkili çalışmadan hazırlanmıştır. 
karakteristiğini belirlemektedir. Oryantal tütünler harmanların içim karakteristiğini iyileştirici, yüksek aromatik özellikleri ile bilinirliğe sahiptir. Oryantal tütünler bu özelliklerine, yetiştirildiği ekoloji ve genetik faktörlerin yanı sira mekanizasyonun daha etkin kullanıldığı broad leaf (iri kıtalı) tütünlere göre, üretim sürecinde ve özellikle kırım, dizim işlemlerinde yapılan yoğun işçilik ile sahip olmaktadır.

Yaprak kenarlarında sararmanın başlaması, yaprak yüzeyinde olgunluk lekelerinin (kurbağalama) belirmesi, yaprak uçlarının sarkması ve kırıldığında tok bir "çıt" sesinin duyulması teknik hasat olgunluğuna gelindiğinin ifadesidir (Kabakçı, 1999). El el kırım işlemi, aynı zamanda olgunluk gösteren, biçim ve boyut bakımından birbirine benzeyen ve "el" adı verilen yaprak kümelerinin aşağıdan yukarıya doğru kırılmasıdır. Farklı zamanlarda hasat edilen el grupları teknik bakımdan 7 grupta (dip, dipüstü, 1. Ana, 2. Ana, 3. Ana, uçaltı ve uç) değerlendirilmekte iken günümüzde kırım sayısına 3 el grubu (alt, ana ve uç eller) konu olmaktadır. Her el grubunun sahip olduğu morfolojik, fiziksel, kimyasal ve degüstatif özellikleri birbirinde farklılık göstermektedir. Fiyatlandırmaya esas olan ekspertiz işleminde kriter olarak el grubundan da yararlanılmaktadır. Örneğin Zorba (2008), Samsun tipi tütünlerde kapa sınıfının başlıca dipüstü el grubu ile diğer el gruplarında $A G$ ve BG'a girmeyen zayıf dokulu, koku niteliği aranmayan, menşe rengini kısmen taşıyan ve yaprak bütünlüğü arızalı yapraklardan oluştuğunu bildirmektedir.

Günümüze kadar farklı hasat yöntemlerinin yaprak kalitesi ve dekara verime etkisini konu alan ulusal ve uluslararası sayısız araştırma yapılmıştır. Oryantal tütünlerde el gruplarının yaprak eni-boyu ile ovalite ve çaplar katsayısı (Peksüslü, 2000) ve kimyasal özellikleri (Sekin ve ark., 1985; Kaba, 1998; Ekren ve Sekin, 2008) üzerine bazı çalışmalar yapılmış, ancak el gruplarının verim ve randıman bakımından ayrı ayrı incelendiği bir çalışmaya rastlanmamıştır. Sadece Mercimek (2016), el el kırımı yapılan tütünleri elek, file ve geleneksel kurutma sistemlerinde kurutmuş ve el gruplarının su kaybı ve verim değerlerini incelemiştir. Araștırıcı, su kaybının kurutma sistemi gözetmeksizin en fazla 1. elde, en az ise 3. elde gerçekleştiğini ve kuru madde oranının en fazla 3 . elde tespit edildiğini bildirmektedir.

Basma tipi tütünler küçük kısmen orta kıtalı olup, renkleri açık kırmızı ve koyu sarıdır. Kokulu, dokusu ince, kalınca ve kadifemsi yapıdadır. Bu özelliklerinden dolayı bazı özel sigara harmanları için sigara sanayinin önemli ve vazgeçilmez harman hatlarından birisidir
(Çamaş ve ark., 2009). 20 yy başlarına kadar üretimde yer alan yerli basma tipleri (Basma 318, Basma 192-23), 2000'li yıllarda yerini yunan basması tiplerine (Xanthi2A, Xanthi81) bırakmıştır. Bu dönüşümün ana nedeni üretim miktarının yetersizliğinden dolayı tütün piyasasında yaşanan talep düşüşüdür. Yeni üretim alanlarına yönelik adaptasyon çalışmalarında farklı kanallardan bölgeye giren yunan basması tipleri başarıyla üretilir olmuştur. Böylece Orta Karadeniz ve Marmara Bölgelerinde günümüz basma üretim hattı oluşmuştur. Bölgeye yeni giren yunan basması tipleri üzerine; bölgede yaşanan varyasyondan faydalanan Çamaş ve ark. $(2009$, 2011) ile Kınay ve Yılmaz (2016)'ın yaptığı ıslah çalışmaları ve kültürel uygulamaların verim ve kaliteye etkilerini konu alan Y1lmaz ve Kınay (2011), Kurt (2011) ve Özcan (2014)'ın yaptığı agronomik çalışmalar yürütülmüştür. $\mathrm{Bu}$ yeni tiplerin bölgeye adaptasyonu henüz tamamlanmamıştır. Özellikle kendine has bir kültürü olan oryantal tütün üretiminde tiplere ait özelliklerin keşfedilmesi ve olumsuz yönlerine ait tedbirlerin alınması zaman almaktadır. Örneğin bu tütünler içinde olgunlaşma periyodu kısa olan tipler mevcuttur. Yavaş olgunlaşma özelliği gösteren yerli popülasyonlara alışkanlık gösteren üreticiler kırım sürecinde geç kalmakta, bu tipler selekte edilse dahi üreticiler arasındaki tohumluk alışverişleri durumu zorlaştırmaktadır. $\mathrm{Bu}$ nedenle uzun süreli programlar geliştirilmeli ve bölge tütün tipleri her yönüyle çalışılmalıdır. Önceki çalışmalar incelendiğinde oryantal tütünde el grupları arasında verim ve randıman özelliklerinin tespitine yönelik eksiklik tespit edilmiştir. $\mathrm{Bu}$ çalışma ile farklı oryantal tütün tipleri, el gruplarına göre verim ve randıman özellikleri bakımından karşılaş̧tırılarak değerlendirilmeye çalışılmıştır.

\section{Materyal ve Yöntem}

\subsection{Materyal}

Çalışma materyalini bölgede kullanılan 4 standart çeşit/hat (Xanthi2A, Nail, Canik, Xanthi81) ile Orta Karadeniz Bölgesi basma hattından tek bitki olarak toplanan, DNA parmak izi analizlerine tabi tutularak selekte edilmiş 21 genotip oluşturmaktadır. Tarla denemeleri 2017 yılında 4 farklı lokasyonda (ErbaaKarayaka, Erbaa-Evciler, Gümüşhacıköy ve Bafra), tesadüf blokları deneme deseninde 3 tekrarlı olarak kurulmuştur.

Çizelge 1. Çalışmanın yürütüldüğü lokasyonlara ait kırım tarihleri

\begin{tabular}{lcccc}
\hline \multirow{2}{*}{ Kırımlar } & \multicolumn{4}{c}{ Lokasyonlar } \\
\cline { 2 - 5 } & Evciler & Karayaka & Gümüşhackköy & Bafra \\
\hline 1. Kırım & 03.07 .2017 & 27.06 .2017 & 03.08 .2017 & 15.08 .2017 \\
2. Kırım & 18.07 .2017 & 11.07 .2017 & 23.08 .2017 & 04.09 .2017 \\
3. Kırım & 12.08 .2017 & 08.08 .2017 & 23.09 .2017 & 26.09 .2017 \\
\hline
\end{tabular}


Karayaka ve Bafra arazileri hafif alkali, Evciler ve Gümüşhacıköy arazileri ise orta alkali karakterli olup, organik madde bakımından en zengin arazi Gümüşhacıköy'dür. Karayaka ve Bafra organik maddece orta seviyede olup en fakiri Evciler'dir. Potasyum yönünden tamamı zengin olan arazilerde Karayaka dışındakiler fosfor bakımından fakirdir. Gümüşhacıköy ve Bafra arazileri kumlu-siltli, Karayaka kumlu-tınlı ve Evciler killi-kumlu yapıdadır. Vejetasyon dönemi olan Nisan-Ekim dönemi uzun yıllar ile deneme yılı nispi nem değerlerinde Erbaa'da \% 11.35,
Gümüşhacıköy'de \% 7.75 ve Bafra'da \% 5.61 artış yaşanmıştır. Aynı karşılaştırma aylık sıcaklık ortalamasında Erbaa'da $-0.6^{\circ} \mathrm{C}$, Gümüşhacıköy'de $+0.6^{\circ} \mathrm{C}$ ve Bafra'da $+0.3^{\circ} \mathrm{C}$ değişim olarak tespit edilmiştir. Uzun yıllarla deneme yılı aylık toplam yağış değişimleri vejetasyon döneminde Erbaa'da $-5.2 \mathrm{~mm}$, Gümüşhackköy'de $-6.2 \mathrm{~mm}$ ve Bafra'da $-25 \mathrm{~mm}$ olarak gerçekleşmiştir. Hasat işlemi 3 elde tamamlanan yapraklar (Çizelge 1) el ile dizilerek 1-2 gün soldurma sonrası kurutma alanlarına alınmıştır.

Çizelge 2. Tütün hatlarının farklı el gruplarına ait yaprak verimi $\left(\mathrm{kg} \mathrm{da}^{-1}\right)$ değerleri

\begin{tabular}{|c|c|c|c|c|c|c|c|c|c|c|c|c|c|c|c|c|}
\hline \multirow{2}{*}{ Hatlar } & \multicolumn{4}{|c|}{ Evciler } & \multicolumn{4}{|c|}{ Karayaka } & \multicolumn{4}{|c|}{ Gümüșhacıköy } & \multicolumn{4}{|c|}{ Bafra } \\
\hline & $1 K$ & $2 K$ & $\mathbf{K}$ & Top. & $1 K$ & $2 K$ & $\mathbf{K}$ & on. & $1 \mathrm{~K}$ & $2 K$ & $3 K$ & op. & $1 K$ & $2 K$ & $\mathbf{K}$ & on. \\
\hline & & & & & & & & & 2 & & & & & & 1 & \\
\hline & & & & & & & & & & & & & & & & \\
\hline & a & & 2 & 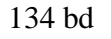 & . & c & & & 28 & & & & & & & \\
\hline & 6 af & & $49 a$ & $162 \mathrm{a}$ & 51 & $77 \mathrm{ae}$ & $\mathrm{ac}$ & & 28 & 9 & & & 1 & & & \\
\hline & $1 \mathrm{cg}$ & ce & $31 \mathrm{~b}$ & $\mathrm{dg}$ & 56 & $1 \mathrm{ad}$ & & & 21 & 88 & & & 6 & & & $\mathrm{ch}$ \\
\hline & $\mathrm{cg}$ & & & & & & & & 0 & & & & 1 & & bg & \\
\hline & & & & & & & & & 29 & & & & & & & \\
\hline & & & & & & & & & & & & & & & & \\
\hline & & & & & & & & & & & & & & & af & $a b$ \\
\hline & fh & & & & & $9 \mathrm{ae}$ & & & 2 & & & & & & $87 \mathrm{a}$ & \\
\hline & $\mathrm{ho}$ & $\mathrm{cf}$ & & & & e & & & 2 & 95 & & & 39 & & & i. \\
\hline & $\mathrm{ab}$ & ce & gh & & & & & & & & & & 72 & & & \\
\hline & $\mathrm{a}$ & h & & & & & & & 1 & & & & 50 & & ag & at \\
\hline & & & & & & & & & & & & & & & & \\
\hline & h & & & & & & & & & & & & & & $\mathrm{ad}$ & \\
\hline & & & & & & e & & & U & & & & 12 & & $79 \mathrm{ac}$ & bg \\
\hline & $\mathrm{ch}$ & & & & & & & & 29 & & & & 0 & & ag & ae \\
\hline & ae & 48 ce & $4 \mathrm{ch}$ & & & & & & 3 & & & & 66 & & & ae \\
\hline & & & & & & & & & 2 & & & & U & & 56 & \\
\hline & & & & & & & & & 2 & & & & & & & \\
\hline & & & & & & & & & 2 & & & & 5 & & & \\
\hline & & & & & & & & & 2 & & & & 43 & & $\mathrm{cg}$ & \\
\hline & & $41 \mathrm{eh}$ & $8 \mathrm{ac}$ & & & be & 7 ae & & 28 & 105 & & & 73 & $c d$ & 4 eg & 8 hi \\
\hline & $\mathrm{ad}$ & $\mathrm{cf}$ & & & $71 \mathrm{ac}$ & & & & 29 & 98 & & & 72 & & $35 \mathrm{eg}$ & 202 bf \\
\hline & $\mathrm{dh}$ & gi & $12 \mathrm{gh}$ & & $59 \mathrm{bd}$ & ce & & & 32 & 96 & $95 \mathrm{ab}$ & $\mathrm{ad}$ & 65 & $94 a$ & $31 \mathrm{fg}$ & 190 ei \\
\hline & & 46 & & & & & & & 20 & & & & & & & \\
\hline & & & & & & & & & & & & & & & & \\
\hline & & & & & 20.1 & & & 13.2 & 24.7 & 18.6 & & 10 & 19.6 & 13.1 & 17.5 & \\
\hline
\end{tabular}

* Her sütunda aynı harflerle gösterilen ortalamalar arasında 0.05 düzeyinde fark yoktur.

\subsection{Metot}

Kurumasını tamamlayan tütünler el gruplarına göre ayrı ayrı tartılmış, nem miktarı \%17'ye sabitlenerek dekara verimler hesaplanmıştır. Ardından ekspertiz (organoleptik gözlem) değerlendirmesi yapılarak genotiplerin el gruplarına ait randıman değerleri ayrı ayrı yüzde cinsinden tespit edilmiştir. Ortalama randıman değerleri ve el gruplarının toplam verimdeki payları yüzde olarak hesaplanmıştır (Kurt, 2011). Her lokasyon ve kırımlar ayrı ayrı olmak üzere veriler varyans analizine tabi tutulmuş, Duncan çoklu karşılaştırma testi ile karşılaştırılmıştır. Tüm analizler SAS 9.0 programı kullanılarak yapılmıştır.

\section{Bulgular ve Tartışma}

Verim değerlerine ait varyans analizi ve çoklu karşılaştırma sonuçları Çizelge 2'de ve el gruplarının lokasyonlara göre verimdeki payları Çizelge 3'te verilmiștir. Evciler lokasyonunda her 3 kırımda ve toplamda verim istatistiki olarak 0.01 düzeyinde önemlidir. Evciler'de birinci kırım değerleri $27-60 \mathrm{~kg}$ $\mathrm{da}^{-1}$ arasında değişmiş, en yüksek değer Erb-7 hattında gerçekleşmiştir. İkinci kırımda en yüksek değer $67 \mathrm{~kg}$ $\mathrm{da}^{-1}$ ile Erb-21 ve 3. kırımda ise $51 \mathrm{~kg} \mathrm{da}^{-1}$ ile Erb-19 hatlarındadır.

Kırım toplamlarından elde edilen verilere göre Evciler lokasyonunda en yüksek verim değerine $167 \mathrm{~kg} \mathrm{da}^{-1}$ ile Erb-21'de ulaşılmıştır. Evciler'de birinci ve ikinci kırımın toplam verimdeki payı üçüncü kırımdan daha yüksektir (Şekil 1). Evciler'de lokasyon 
ortalaması $118 \mathrm{~kg} \mathrm{da}^{-1}$ olmuş, en düşük değer $79 \mathrm{~kg} \mathrm{da}^{-1}$ ile Xanthi2A'da gerçekleşmiştir. Karayaka'da üç kırım ve toplam verim açısından hatlar arasında 0.01 düzeyinde önemli fark bulunmuş, en yüksek verim değerleri birinci kırımda $86 \mathrm{~kg} \mathrm{da}^{-1}$ ile Erb-27, ikinci kırımda $98 \mathrm{~kg} \mathrm{da}^{-1}$ ile Erb-27 ve Erb-35, üçüncü kırımda $75 \mathrm{~kg} \mathrm{da}^{-1}$ ile Erb-16'da tespit edilmiştir.
Toplam verim bakımından Karayaka'da en yüksek değeri $237 \mathrm{~kg} \mathrm{da}{ }^{-1}$ ile Erb-27'de gerçekleşmiştir. Karayaka'da verime en yüksek katkıyı ikinci kırım yaparken, en düşük katkıyı 3. kırım yapmıştır (Şekil 1). Karayaka'da lokasyon ortalaması $184 \mathrm{~kg} \mathrm{da}^{-1}$ olmuş, en düşük değer kg da ${ }^{-1}$ ile Xanthi81'de gerçekleşmiştir.

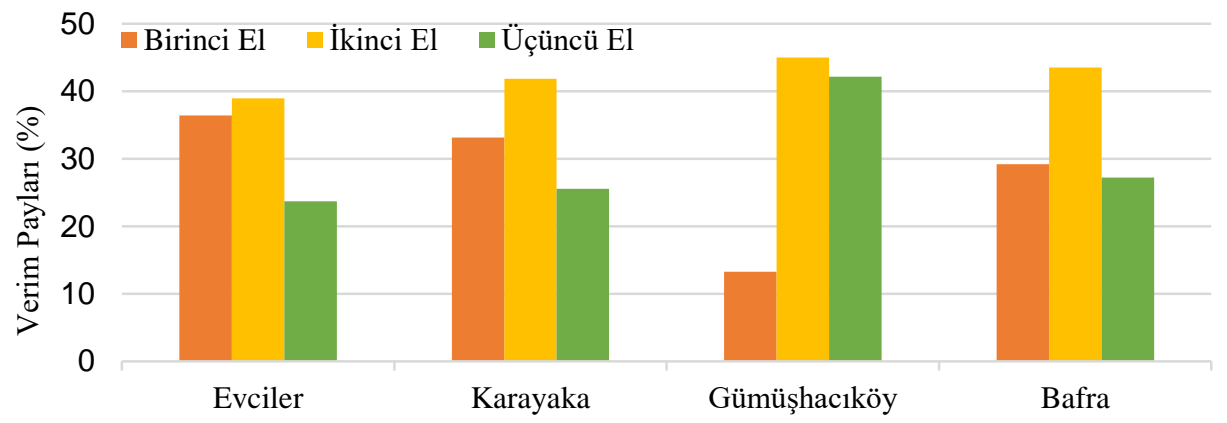

Şekil 1. El gruplarının lokasyonlara göre toplam verimdeki payları

Gümüşhacıköy'de birinci ve ikinci kırım yapılan analiz ile önemsiz, üçüncü kırım ile toplam verim 0.05 düzeyinde önemli bulunmuştur. Üçüncü kırım verimi bakımından en yüksek değer Canik standart çeşidinde $106 \mathrm{~kg} \mathrm{da}^{-1}$ ile tespit edilmiştir.

Toplam verim değerleri bakımından Gümüşhacıköy'de Canik çeşidinin yanı sıra Erb-27, Erb-35 ve Erb-38 öne çıkmaktadır. İkinci e üçüncü kırımlar, ilk kırıma göre verime katkı veya toplam verimdeki payları bakımından yüksek ve bu iki elin etkisi benzerdir (Şekil 1). Gümüşhacıköy'de lokasyon ortalamas1 $211 \mathrm{~kg} \mathrm{da}^{-1}$ olmuş, en düşük değer $174 \mathrm{~kg} \mathrm{da}{ }^{-1}$ ile Erb-15'de gerçekleşmiştir. Bafra lokasyonunda birinci kırım istatistiki olarak önemsiz bulunurken, ikinci kırım 0.05 düzeyinde, üçüncü kırım ve toplam verim 0.01 düzeyinde önemli bulunmuştur. $101 \mathrm{~kg} \mathrm{da}^{-1}$ ile ikinci kırımda en yüksek verim değeri Erb-18' de, toplam verimde ise $226 \mathrm{~kg} \mathrm{da}^{-1}$ ile Erb-16' $\mathrm{da}$ tespit edilmiştir. Verime en yüksek katkıyı ikinci kırım yapmıştır (Şekil 1). Bafra'da lokasyon ortalaması 202 $\mathrm{kg} \mathrm{da} a^{-1}$ olmuş, en düşük değer $173 \mathrm{~kg} \mathrm{da}^{-1}$ ile Xanthi2A'da gerçekleşmiştir.

Tütün genotiplerinde farklı el gruplarının randımanlarına ait varyans analizi ve çoklu karşılaştırma sonuçları Çizelge 4'te, el gruplarının lokasyonlara göre randıman değerleri Şekil 2'de verilmektedir

Çizelge 3. El gruplarının lokasyonlara göre toplam verimdeki payları (\%)

\begin{tabular}{|c|c|c|c|c|}
\hline \multirow{2}{*}{ Lokasyonlar } & \multirow{2}{*}{$\begin{array}{c}\text { Toplam Verim } \\
\text { (Lokasyon Ort., } \mathrm{kg} \mathrm{da}^{-1} \text { ) }\end{array}$} & \multicolumn{3}{|c|}{ El Gruplarının Toplam Verimdeki Payları (\%) } \\
\hline & & Birinci El & İkinci El & Üçüncü El \\
\hline Evciler & 118 & 36.8 & 39.3 & 23.9 \\
\hline Karayaka & 184 & 33.0 & 41.6 & 25.4 \\
\hline Gümüşhacıköy & 211 & 13.2 & 44.8 & 42.0 \\
\hline Bafra & 202 & 29.2 & 43.6 & 27.2 \\
\hline Ortalama & 179 & 28.0 & 42.4 & 29.6 \\
\hline
\end{tabular}

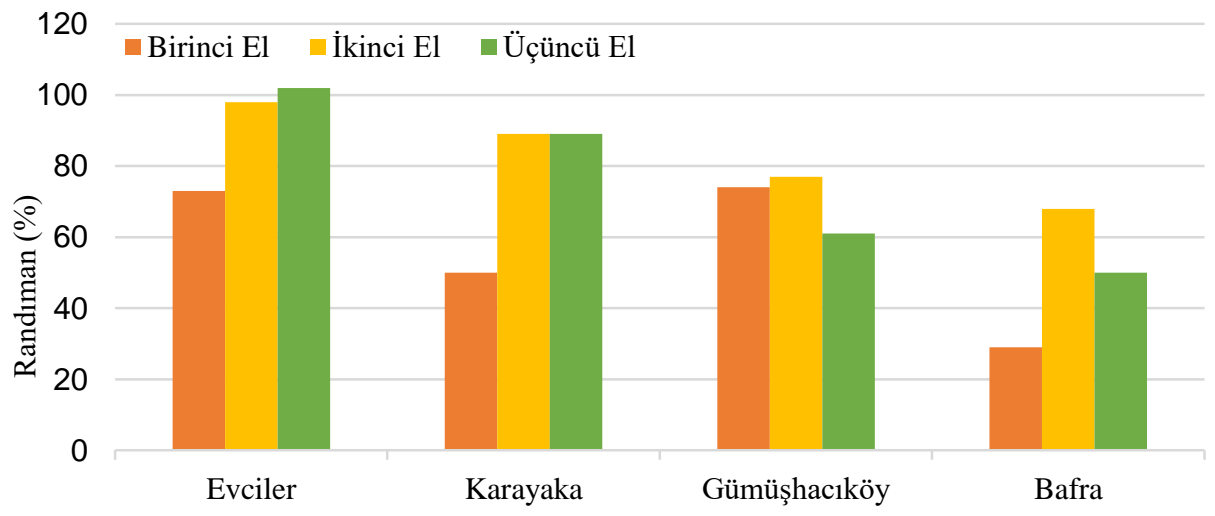

Şekil 2. El gruplarının lokasyonlara göre randıman değerleri 
Çizelge 4. Tütün hatlarının farklı el gruplarına ait randıman (\%) değerleri

\begin{tabular}{|c|c|c|c|c|c|c|c|c|c|c|c|c|c|c|c|c|}
\hline \multirow[t]{2}{*}{ Hatlar } & \multicolumn{4}{|c|}{ Evciler } & \multicolumn{4}{|c|}{ Karayaka } & \multicolumn{4}{|c|}{ Gümüșhacıköy } & \multicolumn{4}{|c|}{ Bafra } \\
\hline & $1 K$ & $2 K$ & $3 K$ & Ort. & $1 K$ & $2 K$ & $3 K$ & Ort. & $1 K$ & $2 K$ & $3 K$ & Ort. & $1 K$ & $2 K$ & $3 K$ & 0 \\
\hline b-5 & 80 & $110 \mathrm{a}$ & $110 \mathrm{a}$ & $96 \mathrm{ad}$ & $53 \mathrm{ab}$ & $100 \mathrm{ab}$ & $100 \mathrm{ab}$ & 75 ae & $73 \mathrm{ac}$ & $67 \mathrm{ac}$ & $60 \mathrm{ae}$ & $65 \mathrm{fi}$ & 37 & $100 \mathrm{a}$ & $53 \mathrm{ac}$ & $69 \mathrm{a}$ \\
\hline rb-6 & 67 & $100 \mathrm{ab}$ & $100 \mathrm{ab}$ & $91 \mathrm{ce}$ & $53 \mathrm{ab}$ & $90 \mathrm{bc}$ & $90 \mathrm{bc}$ & $76 \mathrm{ad}$ & $67 \mathrm{ac}$ & $80 \mathrm{ac}$ & $67 \mathrm{ad}$ & $72 \mathrm{dg}$ & 20 & $67 \mathrm{bc}$ & $53 \mathrm{ac}$ & $1 \mathrm{ae}$ \\
\hline bb-7 & 80 & $110 \mathrm{a}$ & $110 \mathrm{a}$ & $97 \mathrm{ac}$ & $53 \mathrm{ab}$ & $110 \mathrm{a}$ & $110 \mathrm{a}$ & $80 a b$ & $73 \mathrm{ac}$ & $73 \mathrm{ac}$ & $73 \mathrm{ac}$ & $73 \mathrm{df}$ & 40 & $0 \mathrm{ac}$ & $60 \mathrm{ac}$ & $62 \mathrm{ac}$ \\
\hline rb-9 & 60 & $80 \mathrm{~b}$ & $100 \mathrm{ab}$ & $80 \mathrm{gh}$ & $37 \mathrm{bc}$ & $90 \mathrm{bc}$ & $90 \mathrm{bc}$ & $65 \mathrm{bg}$ & $47 \mathrm{c}$ & $47 \mathrm{c}$ & $40 \mathrm{dg}$ & $44 \mathrm{k}$ & 10 & $60 \mathrm{~cd}$ & $40 \mathrm{~cd}$ & $39 \mathrm{df}$ \\
\hline cb- 1 & 60 & $80 \mathrm{~b}$ & $80 \mathrm{c}$ & $73 \mathrm{i}$ & $40 \mathrm{ab}$ & $60 \mathrm{e}$ & $60 \mathrm{e}$ & $49 \mathrm{gh}$ & $90 \mathrm{a}$ & $67 \mathrm{ac}$ & $67 \mathrm{ad}$ & $69 \mathrm{eh}$ & 20 & 53 ce & $37 \mathrm{~cd}$ & $39 \mathrm{df}$ \\
\hline rb-12 & 80 & $110 \mathrm{a}$ & $110 \mathrm{a}$ & $97 \mathrm{ac}$ & $60 \mathrm{a}$ & $80 \mathrm{bd}$ & $80 \mathrm{bd}$ & 68 af & $80 a b$ & $67 \mathrm{ac}$ & $60 \mathrm{ae}$ & $65 \mathrm{fi}$ & 20 & $73 \mathrm{ac}$ & $73 \mathrm{a}$ & $56 \mathrm{ad}$ \\
\hline bb-1 & 80 & $110 \mathrm{a}$ & $110 \mathrm{a}$ & $99 \mathrm{ab}$ & $60 \mathrm{a}$ & $80 \mathrm{bd}$ & $80 \mathrm{bd}$ & 70 af & $90 \mathrm{a}$ & $67 \mathrm{ac}$ & $90 \mathrm{a}$ & $80 \mathrm{ad}$ & 40 & $90 \mathrm{ab}$ & $53 \mathrm{ac}$ & $67 \mathrm{ab}$ \\
\hline $\mathrm{rb}$ & 73 & $90 \mathrm{ab}$ & a & 92 ce & $7 \mathrm{ab}$ & 80 & bd & $62 \mathrm{cg}$ & $3 \mathrm{ac}$ & $60 \mathrm{bc}$ & $53 \mathrm{bf}$ & $9 \mathrm{hj}$ & 40 & $80 \mathrm{ac}$ & ac & $58 \mathrm{ad}$ \\
\hline $\mathrm{rb}$ & 80 & $110 \mathrm{a}$ & a & $100 \mathrm{a}$ & $7 \mathrm{ab}$ & $90 \mathrm{bc}$ & $90 \mathrm{bc}$ & $66 \mathrm{bf}$ & $67 \mathrm{ac}$ & $93 \mathrm{ab}$ & $90 \mathrm{a}$ & $88 \mathrm{al}$ & 20 & $80 \mathrm{ac}$ & $60 \mathrm{ac}$ & $57 \mathrm{ad}$ \\
\hline rb- & 73 & $100 \mathrm{ab}$ & $90 \mathrm{bc}$ & 89 ef & $40 \mathrm{ab}$ & $80 \mathrm{bd}$ & $80 \mathrm{bd}$ & $62 \mathrm{cg}$ & $83 \mathrm{a}$ & $90 \mathrm{ab}$ & $60 \mathrm{ae}$ & $77 \mathrm{c}$ & 20 & $37 \mathrm{de}$ & $53 \mathrm{ac}$ & $40 \mathrm{df}$ \\
\hline$b-1$ & 73 & $90 \mathrm{ab}$ & $110 \mathrm{a}$ & $85 \mathrm{fg}$ & $40 \mathrm{ab}$ & $90 \mathrm{bc}$ & $90 \mathrm{bc}$ & $61 \mathrm{cg}$ & $67 \mathrm{ac}$ & $53 \mathrm{c}$ & $37 \mathrm{eg}$ & $48 \mathrm{k}$ & 30 & 53 ce & $47 \mathrm{bc}$ & 46 be \\
\hline rb- & 67 & $80 \mathrm{~b}$ & $80 \mathrm{c}$ & $77 \mathrm{hi}$ & $47 \mathrm{ab}$ & $80 \mathrm{bd}$ & $80 \mathrm{bd}$ & $61 \mathrm{dg}$ & $80 a b$ & $67 \mathrm{ac}$ & $30 \mathrm{fg}$ & $53 \mathrm{jk}$ & 30 & $30 \mathrm{e}$ & $47 \mathrm{bc}$ & 33 ef \\
\hline Erb-1 & 73 & $100 \mathrm{ab}$ & $100 \mathrm{ab}$ & $90 \mathrm{df}$ & $60 \mathrm{a}$ & $110 \mathrm{a}$ & $110 \mathrm{a}$ & $84 \mathrm{a}$ & $90 \mathrm{a}$ & $100 \mathrm{a}$ & $73 \mathrm{ac}$ & $87 \mathrm{ac}$ & 43 & $67 \mathrm{bc}$ & $40 \mathrm{~cd}$ & $57 \mathrm{ad}$ \\
\hline Erb-2 & 60 & $90 \mathrm{ab}$ & $100 \mathrm{ab}$ & $80 \mathrm{gh}$ & $53 \mathrm{ab}$ & $80 \mathrm{bd}$ & $80 \mathrm{bd}$ & $66 \mathrm{bf}$ & $73 \mathrm{ac}$ & $100 \mathrm{a}$ & $73 \mathrm{ac}$ & $85 \mathrm{ac}$ & 40 & $73 \mathrm{ac}$ & $53 \mathrm{ac}$ & $59 \mathrm{ad}$ \\
\hline Erb & 80 & $110 \mathrm{a}$ & $100 \mathrm{ab}$ & $95 \mathrm{ad}$ & $a b$ & $80 \mathrm{bd}$ & $80 \mathrm{bd}$ & 66 bf & $67 \mathrm{ac}$ & $77 \mathrm{ac}$ & $50 \mathrm{bf}$ & $65 \mathrm{fi}$ & 53 & $80 \mathrm{ac}$ & $67 \mathrm{ab}$ & 68 \\
\hline $\mathrm{rb}$ & 67 & $80 \mathrm{~b}$ & $\mathrm{c}$ & $76 \mathrm{hi}$ & $40 \mathrm{ab}$ & $73 \mathrm{ce}$ & 73 ce & $58 \mathrm{fg}$ & $53 \mathrm{bc}$ & $77 \mathrm{ac}$ & $43 \mathrm{cg}$ & $61 \mathrm{hj}$ & 10 & $60 \mathrm{~cd}$ & $47 \mathrm{bc}$ & $44 \mathrm{ce}$ \\
\hline Erb-2 & 73 & $110 \mathrm{a}$ & $110 \mathrm{a}$ & 94 ae & $60 \mathrm{a}$ & $100 \mathrm{ab}$ & $100 a b$ & $79 \mathrm{ab}$ & $67 \mathrm{ac}$ & $73 \mathrm{ac}$ & $40 \mathrm{dg}$ & $58 \mathrm{ij}$ & 10 & $67 \mathrm{bc}$ & $53 \mathrm{ac}$ & $49 \mathrm{ae}$ \\
\hline rb- & 67 & $80 \mathrm{~b}$ & $80 \mathrm{c}$ & $76 \mathrm{hi}$ & $20 \mathrm{c}$ & $67 \mathrm{de}$ & $67 \mathrm{de}$ & $40 \mathrm{~h}$ & $73 \mathrm{ac}$ & $60 \mathrm{bc}$ & $20 \mathrm{~g}$ & $46 \mathrm{k}$ & 10 & $37 \mathrm{de}$ & $20 \mathrm{~d}$ & $24 \mathrm{f}$ \\
\hline Erb-3 & 80 & $100 \mathrm{ab}$ & $100 \mathrm{ab}$ & 93 be & $60 \mathrm{a}$ & $80 \mathrm{bd}$ & $80 \mathrm{bd}$ & 70 af & $80 \mathrm{ab}$ & $100 \mathrm{a}$ & $80 \mathrm{ab}$ & $90 \mathrm{a}$ & 30 & $67 \mathrm{bc}$ & $40 \mathrm{~cd}$ & $49 \mathrm{ae}$ \\
\hline rb-3 & 60 & $100 \mathrm{ab}$ & $110 \mathrm{a}$ & $81 \mathrm{gh}$ & $60 \mathrm{a}$ & $100 \mathrm{ab}$ & $100 \mathrm{ab}$ & $79 a b$ & $73 \mathrm{ac}$ & $100 \mathrm{a}$ & $73 \mathrm{ac}$ & $85 \mathrm{ac}$ & 20 & $73 \mathrm{ac}$ & $47 \mathrm{bc}$ & $56 \mathrm{ad}$ \\
\hline $\mathrm{cb}_{3}$ & 80 & $110 \mathrm{a}$ & $110 \mathrm{a}$ & $97 \mathrm{ac}$ & $53 \mathrm{ab}$ & $110 \mathrm{a}$ & $110 \mathrm{a}$ & $78 \mathrm{ac}$ & $77 \mathrm{ab}$ & $90 \mathrm{ab}$ & $80 \mathrm{ab}$ & $84 \mathrm{ac}$ & 30 & $80 \mathrm{ac}$ & $47 \mathrm{bc}$ & $54 \mathrm{ad}$ \\
\hline Xant2 & 80 & $110 \mathrm{a}$ & $110 \mathrm{a}$ & $97 \mathrm{ac}$ & $60 \mathrm{a}$ & $110 \mathrm{a}$ & $110 \mathrm{a}$ & $82 \mathrm{a}$ & $90 \mathrm{a}$ & $100 \mathrm{a}$ & $53 \mathrm{bf}$ & 79 be & 30 & $67 \mathrm{bc}$ & $47 \mathrm{bc}$ & $51 \mathrm{ae}$ \\
\hline Nail & 80 & $90 \mathrm{ab}$ & $110 \mathrm{a}$ & $95 \mathrm{ae}$ & $53 \mathrm{ab}$ & $90 \mathrm{bc}$ & $90 \mathrm{bc}$ & 68 af & $60 \mathrm{ac}$ & $60 \mathrm{bc}$ & $67 \mathrm{ad}$ & $62 \mathrm{gj}$ & 40 & $80 \mathrm{ac}$ & $53 \mathrm{ac}$ & $61 \mathrm{ac}$ \\
\hline Canik & 73 & $100 \mathrm{ab}$ & $110 \mathrm{a}$ & 95 ae & $47 \mathrm{ab}$ & $80 \mathrm{bd}$ & $80 \mathrm{bd}$ & $59 \mathrm{eg}$ & $67 \mathrm{ac}$ & $73 \mathrm{ac}$ & $67 \mathrm{ad}$ & $69 \mathrm{eh}$ & 37 & $73 \mathrm{ac}$ & $60 \mathrm{ac}$ & $59 \mathrm{ad}$ \\
\hline Xant81 & 80 & $110 \mathrm{a}$ & $110 \mathrm{a}$ & $96 \mathrm{ad}$ & $60 \mathrm{a}$ & $110 \mathrm{a}$ & $110 \mathrm{a}$ & $80 \mathrm{ab}$ & $90 \mathrm{a}$ & $73 \mathrm{ac}$ & $73 \mathrm{ac}$ & $77 \mathrm{ce}$ & 40 & $73 \mathrm{ac}$ & $53 \mathrm{ac}$ & $58 \mathrm{ad}$ \\
\hline & 73 & 98 & 102 & 90 & 50 & 89 & 89 & 68 & 74 & 77 & 61 & 70 & 29 & 68 & 50 & 52 \\
\hline & & $56^{* *}$ & $39 * *$ & $63 * *$ & $63 * *$ & $01 * *$ & $.01 * *$ & $.78 * *$ & $1.76^{*}$ & $59 * *$ & $34 *$ & $59 * *$ & .35 & $31 * *$ & $2.14 *$ & $3.38^{* * *}$ \\
\hline CV $(\%)$ & 3.8 & 10.9 & 9.1 & 3.4 & 21.2 & 11.3 & 11.3 & 12.3 & 20.2 & 22.5 & 21.9 & 8.13 & 21.1 & 20.1 & 21.8 & 19.87 \\
\hline
\end{tabular}

* Her sütunda aynı harflerle gösterilen ortalamalar arasında 0.05 düzeyinde fark yoktur.

Çizelge incelendiğinde Evciler lokasyonunda birinci kırımın önemsiz, ikinci kırım, üçüncü kırım ve ortalama randımanın 0.01 düzeyde önemli olduğu görülmektedir. Birinci kırım randıman ortalamas1 \% 73 iken, ikinci kırım \% 98 ve üçüncü kırım \% 102'dir. Ortalama randıman ise mahsulün tümüne ait olup, kırımların verime olan katkıları oranında oluştuğu için Evciler'de $\% 90$ olarak ortaya çıkmıştır. Bu nedenle en yüksek randımanlar teorik olarak farklı genotiplerde ikinci ve üçüncü kırımlarda \% 110 olarak oluşmuşken, pratikte Erb-15'te \% 100 olarak tespit edilmiştir. Erb-11\% 73 ile Evciler'de en düşük randıman değerin sahip genotip olmuştur.

Karayaka'da her 3 kırım ve ortalama randıman 0.01 düzeyinde önemlidir. Farklı genotiplerde birinci kırımda $\% 60$ ve ikinci ile üçüncü kırımda \% 110 en yüksek randıman değerleridir. Ortalama randıman bakımından Erb-19 \% 84 randıman ile en yüksek ve Erb-27 \% 40 randıman ile en düşük değerlere sahiptir. Karayaka'da genotiplerin randıman ortalaması \% 68 olarak gerçekleşmiş, birinci kırımların aksine ikinci ve üçüncü kırımların randımanları daha yüksektir.

Gümüşhacıköy'de farklı genotiplerin randıman değerleri birinci kırımda 0.05 , ikinci kırım, üçüncü kırım ve ortalama randıman değerleri 0.01 düzeyinde önemli bulunmuştur. Bu lokasyonda randıman değerleri birinci kırımda \% 47-90, ikinci kırımda \% 47-100 ve üçüncü kırımda \% 20-90 arasında değişmiş, üçüncü kırım randıman değerleri daha düşük bulunmuştur. Randıman bakımından lokasyon ortalaması \% 70 iken en yüksek randıman Erb-30'da \% 90 ve en düşük \% 44 ile Erb-9'da tespit edilmiştir.

Bafra lokasyonu randıman değerleri incelendiğinde istatistiki olarak birinci kırım önemsiz, üçüncü kırım 0.05 düzeyinde ve ikinci kırım ve ortalama randıman değerleri 0.01 düzeyinde önemli olarak tespit edilmiştir. Birinci kırımlarda \%53 ile Erb-23, ikinci kırımlarda \% 100 ile Erb-5 ve üçüncü kırımlarda \% 73 ile Erb-12 en yüksek randıman değerlerine sahiptir. Genel olarak kapa kalite sınıfında ürün elde edilen birinci kırımlara ek olarak, ikinci kırımda Erb-18 \% 30 ve üçüncü kırımda Erb-27\% 20 randıman ile en düşük değerlere sahiptir. Lokasyon ortalamas $\% 52$ olarak gerçekleşen randıman değeri, en düşük olarak birinci kırımlardan elde edilmiştir. Randıman diğer lokasyonların aksine sadece ikinci kırımlarda kabul edilebilir sınırlar içinde gerçekleşmiştir.

Oryantal tütün yetiştiriciliğinde en önemli unsur olarak karşımıza çıkan verim ve randıman nitelikleri, yetiştiriciliğin yapıldığ kullanılan üretim materyalinin genetik potansiyeli ile de ilişkilidir (Şenbayram ve ark., 2005; Ekren ve Sekin, 2008). Verim ve kalite arasında ki negatif yönlü ilişki birçok araştırma da raporlanmıştır (Paunescu ve ark., 2003; Aytaç, 2016). Genel ortalamalar bakımından Çizelge 2, 3 ve Şekil 3 incelendiğinde artan verim değerlerine karşın azalan randıman değerleri görülebilmektedir. Bazı hatlarda bu durum daha belirgin iken, bazıları artan verim değerlerine karşın kabul edilebilir randıman değerleri ile öne çımaktadır. Erb-7 
hattı tüm lokasyonlarda ortalamanın üzerinde verim ve randıman değerleri sergilemiştir. Erb-9 ve Erb-27 hatları verim bakımından lokasyon ortalamalarının üzerinde iken randımanları ortalamanın altındadır. Erb-19 hattı Gümüşhacıköy'de verim ve Erb-30 hattı Bafra'da randıman dışında, verim ve randıman bakımından tüm lokasyonlarda ortalama değerlerin üzerindedir. Bu hatlar yöre için tavsiye oluşturulacak ıslah çalışmalarında göz önünde bulundurulmalıdır.

Tütün hasadı en az 3 elde yapılmakta ve mahsul, bu 3 elin toplamından oluşmaktadır. Mercimek (2016) yaptığı çalışmasında kurutma sonunda en yüksek su kaybının birinci ellerde yaşandığını ve bunun ikinci ve üçüncü ellerin kuru madde içeriğinin fazlalığından olduğunu bildirmektedir. Yaptığımız çalışma sonuçlarına bakıldığında mahsul veriminde ilk kırımların \% 28.0, ikinci kırımların \% 42.4 ve üçüncü kırımların \% 29.6 oranlarında etkili olduğu anlaşılmaktadır. $\mathrm{Bu}$ oranlar Gümüşhacıköy dışında ki lokasyonlarda birbirine benzer olarak sirasiyla, Evciler'de \% 36.8, 39.3 ve 23.9, Karayaka'da \% 33.0, 41.6 ve 25.4, Bafra'da \% 29.2, 43.6, 27.2'dir.
Gümüşhacıköy'de ise birinci kırımlar \% 13.2, ikinci kırımlar \% 44.8 ve üçüncü kırımlar \% 42.0 paya sahiptir. Tütün, kendine has yöresel üretim kültüründe farklılıkların yaşandığı bir bitkidir. Gümüşhacıköy'de yerleşmiş, iklim faktörlerinin de etkili olduğu geçci üretim ve bu nedenle olgunlaşmada yaşanan yavaşlık ve gecikme nedeniyle ilk kırımda sadece dipüstü el grubu hasat edilmektedir. Bu nedenle diğer lokasyonlara göre ilk kırımda daha az yaprak olgunlaşmakta ve hasat edilmekte, hasadın \% 87'lik kısmı ikinci ve üçüncü kırımlara kalmaktadır. Karayaka ve Gümüşhacıköy mahsul randımanı bakımından benzer değerler gösterirken (\% 68 ve \% 61), el gruplarına ait randıman değerleri farklılık göstermiştir. Lokasyonlar içinde en yüksek mahsül randımanı Evciler'de (\% 90), en düşük ise Bafra'da (\% 52) tespit edilmiştir. Randıman üzerine ilk kırımlar \% 25.8, ikinci kırımlar \% 39.4 ve üçüncü kırımlar \% 34.8 oranlarında etkilidir. Mahsulün fiyatlandırılmasında esas teşkil eden randımanın ortaya çıkmasında en etkili kırımların ikinci ve üçüncü kırımlar olduğu şüphesizdir.

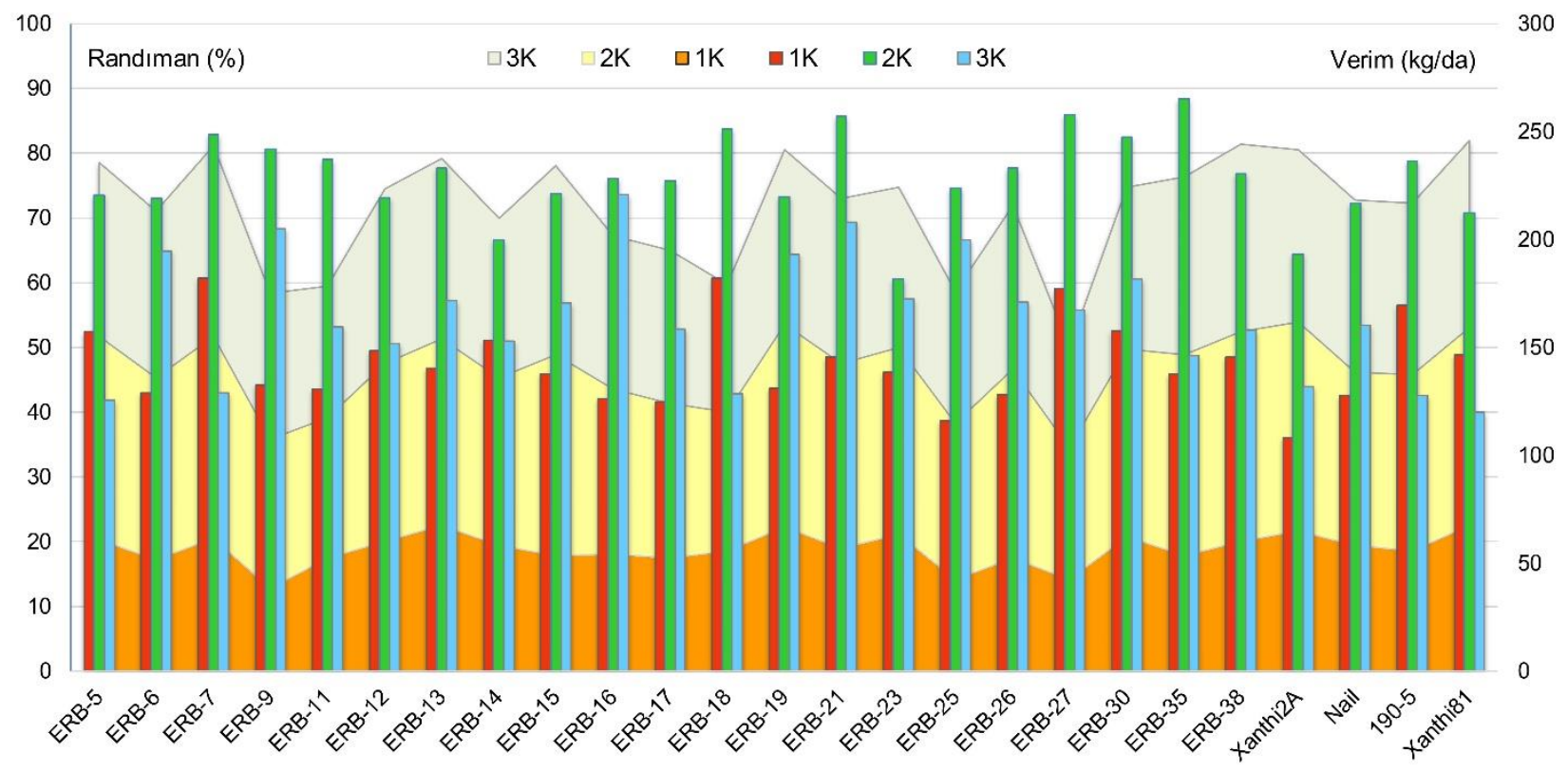

Şekil 3. Tütün hatlarının farklı el gruplarına ait verim $\left(\mathrm{kg} \mathrm{da}^{-1}\right)$ ve randıman $(\%)$ değişimleri

\section{Sonuç}

Sonuç olarak çalışmaya konu olan tütün hatlarının el grupları arasında verim ve randıman değerleri bakımından farklılıkların olduğu tespit edilmiştir. Fiyatlandırmada etkili olan randıman ve üreticinin toplam gelirinin kaynağı olan verim özelliklerinin buluştuğu hatların üretimde yer alması gerekmektedir. Yüksek verim potansiyeline sahip fakat oransal olarak $\% 60$ 'tan daha az A grad ürüne sahip hatlar üretimden çekilmelidir. Aynı şekilde üretimde tip özelliği olarak yüksek kalite tek başına tercih sebebi olmamalı, kabul edilebilir kalitede mümkün olan en yüksek verime sahip yöreye uygun hatlar/çeşitler tercih edilmelidir. Üretimde yer alan hat/çeşitler, çok lokasyonlu araştırmalara konu edilerek, bu yönde bilgilerin açığa çıkarılmasına yönelik çalışmalar yapılmalıdır. 


\section{Kaynaklar}

Anonim, 2018a. Dünyada tütün ekim alanı ve üretim miktarı. Faostat, http://www.fao.org/faostat/en/data (Erişim tarihi: 05 Nisan 2018).

Anonim, 2018b. Tütün ve Alkol Piyasası Düzenleme Kurumu yaprak tütün piyasası verileri. http://www.tapdk.gov.tr/tr/piyasa-duzenlemeleri/tutunpiyasasi.aspx (Erişim tarihi: 05 Nisan 2018).

Aytaç, B., 2016. Bafranın Farklı Lokasyonlarında Nail Tütün Hattı Performanslarının Belirlenmesi. Yüksek Lisans Tezi. Ondokuz Mayıs Üniversitesi Fen Bilimleri Enstitüsü, 69 s, Samsun.

Çamaş, N., Karaali, H., Çalışkan, Ö., Kurt, D., 2009. Basma tütün çeşit ve hatlarının Gümüşhacıköy şartlarında verim ve verim unsurlarının belirlenmesi. Türkiye VIII. Tarla Bitkileri Kongresi (19-22 Ekim 2009, Hatay) Bildirileri, 247-250.

Çamaş, N., Karaali, H., Kurt, D., Kınay, A., 2011. Orta Karadeniz bölgesi basma tipi tütün yetiştiriciliğinde kalite unsurlarının değerlendirilmesi. Türkiye IX. Tarla Bitkileri Kongresi (12-15 Eylül 2011, Bursa) Bildirileri, 908-913.

Ekren, S., Sekin, S., 2008. Akhisar bölgesi tütünlerinin kimyasal ve ekspertiz özellikleri ve verim ile aralarındaki ilişkilerin saptanması. Ege Üniversitesi Ziraat Fakültesi Dergisi, 45 (3): 165-173.

Kaba, S., 1998. Farklı İki Tütün Çeşidinde Kırım Zamanı ve Kurutma Şeklinin Verim ve Kaliteye Etkisi Üzerine Araştırmalar. Doktora Tezi, Trakya Üniversitesi Fen Bilimleri Enstitüsü, $115 \mathrm{~s}$, Tekirdağ.

Kabakçı, H., 1999. Yenice ve Çevresinde Tütüncülük. Yüksek Lisans Tezi. Çanakkale Onsekiz Mart Üniversitesi Sosyal Bilimleri Enstitüsü, $171 \mathrm{~s}$, Çanakkale.

Kınay, A., Y1lmaz, G. 2016. Effects of heterosis on agronomically important traits of oriental tobacco (Nicotiana tabacum L.) hybrids. Süleyman Demirel Üniversitesi Ziraat Fakültesi Dergisi 11 (1): 89-94.

Kurt, D., 2011. Organik Tütün (Nicotiana tabacum L.) Üretiminde Farklı Gübre Kaynakları ve Kaliteye Etkisi. Yüksek Lisans Tezi. Ondokuz Mayıs Üniversitesi Fen Bilimleri Enstitüsü, 54 s, Samsun.
Mercimek, HV., 2016. Oryantal Tütünde (Nicotiana tabacum L.) Hasat Sonras1 Farklı Kurutma Sistemlerinin Verim ve Kalite Özelliklerine Etkileri. Yüksek Lisans Tezi. Gaziosmanpaşa Üniversitesi Fen Bilimleri Enstitüsü, $113 \mathrm{~s}$, Tokat.

Odabaşoğlu, M., 1994. Tütün Kimyası. Ondokuz Mayıs Üniversitesi Fen Edebiyat Fakültesi Yayınları No: 90. Samsun, $154 \mathrm{~s}$.

Özcan, H., 2014. Tütünde (Nicotiana tabacum L.) Farklı Hasat Şekillerinin Verim ve Kalite Özelliklerine Etkileri. Yüksek Lisans Tezi. Gaziosmanpaşa Üniversitesi Fen Bilimleri Enstitüsü, $51 \mathrm{~s}$, Tokat.

Paunescu M., Paunesu, A.D., Ciuperca, A., Udrecsu, V., Udrescu, E., 2003. Studies concerning the release of new oriental tobacco genotypes with superior charactersitics of taste and aroma, Coresta Meet. Agro-Phyto Groups, Bucharest Abstracts: 27.

Peksüslü, A., 2000. Bazı Türk Tütün Çeşitlerinin İzmirBornova Koşullarında Morfolojik Fizyolojik ve Agronomik Özellikleri. Tarımsal Yayım ve Uygulamalı Araştırma Projesi (TYUAP) Ege Tarımsal Araştırma Enstitüsü Yayınları No: 98, 249-268, İzmir.

Sekin, S., Özçam, A., Ural, A., 1985. Kimi Şark Tipi Tütünlerde Olgunlaşma Sirasında Pigmentler ve Diğer Kimyasal Bileşenlerde Meydana Gelen Değişmeler ve Hasat Sonras1 ve Kurutma Sonuna ait Analitik Karakterler Arasındaki İlişkiler Üzerinde Araştımalar. Tübitak Tovag Grubu TOAG-476 No'lu Proje Sonuç Raporu $85 \mathrm{~s}$.

Şenbayram, M., Ekren, S., Sekin, S., 2005. Ekolojik koşulların ve besin elementlerinin oryantal tütün kalitesi üzerine etkileri. Ege Bölgesinde Tütün Tarımı ve Sorunları Çalıştayı (21 Aralık 2005, İzmir) Bildirileri, 75-89.

Y1lmaz, G., Kınay, A., 2011. Tütünde (Nicotiana tabacum L.) farklı azot dozlarının verim ve kalite özelliklerine etkileri. IX. Tarla Bitkileri Kongresi (12-15 Eylül 2011, Bursa) Bildirileri, 951-956.

Zorba, T., 2008. Karadeniz Bölgesine En Uygun Tütün Çeşit ve Hatlarının Tespiti İle Ürünlerin Ekspertiz Değerleri Üzerine Bir Çalışma. Yüksek Lisans Tezi. Ondokuz Mayıs Üniversitesi Fen Bilimleri Enstitüsü, $52 \mathrm{~s}$, Samsun. 